\title{
A Study on the Impact of Stress on the Selection of New Products and the Intermediary Mechanism during the Process of Goal Pursuit
}

\author{
Chuming Hu, Ying Zhao \\ School of Management, Jinan University, Guangzhou, China \\ Email: zhaoyingschl@163.com
}

How to cite this paper: Hu, C.M. and Zhao, Y. (2018) A Study on the Impact of Stress on the Selection of New Products and the Intermediary Mechanism during the Process of Goal Pursuit. Open Journal of Social Sciences, 6, 242-252.

https://doi.org/10.4236/jss.2018.63017

Received: February 22, 2018

Accepted: March 27, 2018

Published: March 30, 2018

Copyright ( 92018 by authors and Scientific Research Publishing Inc. This work is licensed under the Creative Commons Attribution International License (CC BY 4.0).

http://creativecommons.org/licenses/by/4.0/

\begin{abstract}
Most of what consumers do involves the pursuit of goals, and consumer goals affect consumer behavior [1]. Many studies show that stress always exists in the process of goal pursuit [2]. When coping with stress, consumers change their spending habits [3]. Although the existing research has explained to some extent consumer new product choice behavior, they have neglected the impact of stress on new product choice in the process of chasing goals in everyday life. Based on the research of goal orientation, stress, this study mainly explores the influence of the stress level and on the choice of new products and the moderating effect of regulatory focus, and uses two experiments for empirical research. The first experiment tested the selection of new products by manipulating the stress level. The second experiment can influence the attention point of people by manipulating the stress level, thus verifying the mediating effect of the focus. The results show that consumers are more likely to choose a new product when they are experiencing high levels of stress during the goal pursuit process than when they feel low stress. The reason is that the consumer's focus on the product shifts to the benefits of the product's ability to help achieve the goal in the high levels of stress. The new products are better than the old ones, so people are more willing to choose new products.
\end{abstract}

\section{Keywords}

Stress, Goal Pursuit, New Products Selection, Focus

\section{Introduction}

New products are the keys to competitive advantage and extra profit, but the 
probability of new product failure is very high, and $70 \%$ of new products have been declared unsuccessful in 18 months to two years after release [4]. One of the main reasons is consumer acceptance of new products [5]. Many scholars have tried to attribute new products to the characteristics of consumers themselves, and some scholars have shown that consumer characteristics (such as age, income, lifestyle, etc.) are related to new product adoption behaviors [6]. Although these consumer characteristics explain to some extent the behavior of consumer new product selection, they ignore the influence of people's goal-oriented consumption behavior on the choice of new products in daily life.

People in daily life will set a lot of goals, such as: lose 10 pounds, admit to a prestigious university, cure a disease. All of these goals affect consumer behavior, leading to changes in consumer behaviour. Most of what consumers do involves goal pursuit, while consumer researchers rarely focus on targeted consumer behavior [1]. The research shows that the stress always exists in the process of goal pursuit. When coping with stress, consumers change their spending habits [3].

When consumers are unsure to accomplish the goal, they look for information to make sure they can achieve their goals. They will also take steps to help them achieve their goals [7]. Compared with the old product, the new one with improved performance is easier to help achieve the goal.

Based on the above, this paper will focus on the goal pursuit, and explore the impact of stress levels on new product adoption and its intermediary mechanism.

\section{Theoretical Basis and Research Hypothesis}

\subsection{Goal Pursuit, Stress and New Products}

Once the decision to pursue a goal is made, people will consider how to achieve the goal, i.e. the course of action to achieve the goal [1]. When deciding to fight for goals, people are more concerned not with results, but by the means (tools/methods) to achieve them [8]. Baumgartner (2008) also believes that people pay more attention to how to achieve the goal and the choice of target tools.

There are usually two kinds of new products and old ones in the tools to help achieve goals. Compared with the old products, the new product has improved technical improvement, but at the same time accompanied by risk [9]. Consumers choose new products with two main perceptions: perceptions of product strengths and perceptions of risk to the product [10]. When consumers try new products, they face the dilemma of the benefits that new products bring to them and the risks they face after adopting new products [11].

In the goal struggle phase, when the individual perceives that their own abilities and resources do not meet the requirements of achieving the goal, it will create stress [12]. This kind of stress is caused by a huge gap between the individual's perception of their abilities, their resources and their goals. In the pur- 
suit of goals, many of the actions that consumers make are consistent with goals [1]. When the choice of a target tool is made under stress, the performance of the products that are well known to the market has not been improved, and the likelihood of helping people achieve the goal is relatively low. Consumers will be less willing to choose traditional products when they perceive a lower likelihood of reaching a goal.

When consumers are unsure to accomplish the goal, they look for information to make sure they can achieve their goals. They will also take steps to help them achieve their goals [7]. When goals are less likely to be reached, a more diverse range of alternative approaches to achieving goals increases the motivation associated with the goal [13]. The greater the stress, the greater the perceived gap between the target and the lower the likelihood of achieving the goal. The more people tend to find ways to help themselves achieve their goals. And if there are many ways to achieve goals, people will think more about which approach will be better and easier to achieve [1].

Compared with the old products, new products have improved technology, improved technology can better achieve a certain aspect of the function, achieve better performance [9]. Therefore, new products are more conducive to help achieve the goal. Optimism about the outcome of the goal is expected to increase the willingness of people to implement the goal [14]. The results of an optimistic goal will also encourage people to continue to achieve their goals [1]. Some scholars have pointed out that the choice of tools for achieving goals depends on the expected results [15]. According to the theory of planned behavior, when consumers take into account the greater likelihood that a new product will reach their goal, the perceived control of the consumer is stronger and the new product is chosen as a tool to help the target. The willingness of consumers to choose old products as a tool to help them achieve their goals will also decline as their performance does not give consumers more perceived control over their goals.

To sum up, put forward $\mathrm{H}_{1}$ : in the process of goal pursuit, compared to the lower stress level, higher stress level will make consumers more willing to choose new methods (products).

\subsection{Focus}

Studies have shown that the perceived time stress of promotions make consumers exaggerate perceived gains and reduce perceived risk [16]. This paper points out that the level of stress in the goal pursuit process affects the consumer's focus on the product. That is, as stress levels change, people's focus on the benefits or risks of the product changes.

When considering which product to help achieve goals, people will be influenced by the level of stress that consumers are in. Specifically, people are in a state of high stress when they perceive a wide gap in the resources and capabilities and goals they possess [17]. At this point people need to seek greater support from outside to help them achieve their goals. This makes it more demanding to 
achieve the target tool itself, in order to make up for the gap between abilities and the target's needs, so as to achieve the goal. So when choose tools to help people achieve goals, people will pay more attention to how well the methods (tools/products) bring to their goals. Compared to existing products, improved technology can better achieve a certain aspect of the function, achieve better performance [9], that is, new products can better help consumers achieve goals. People tend to pursue goals in a consistent fashion [18]. In combination with the goal-oriented and planning behavior theory, the more the product is expected to help achieve the goal, the higher the willingness of people to adopt the product. Inference that: the goal of the pursuit process, the greater the stress on people, the more willing to adopt new products.

When consumers perceive that their own resources, capabilities and goals are not very much in demand, people will be in a low stress state [17]. So, at this point, people don't need to seek greater support from outside to help them achieve their goals. This is not a high performance requirement for achieving the target tool. So when choosing tools to help achieve goals, people will not be more concerned with the benefits that methods (tools/products) bring to their goals. In addition to improved technical improvements, new products accompanied by risk [9] will make consumers perceive many uncertainties and risks [19]. It also allows consumers to ignore the effect of new products on their goals, thereby reducing the willingness to adopt new products.

Therefore, put forward $\mathrm{H}_{2}$ : when in a high stress level state, people pay more attention to products (methods) for the purpose of the pursuit of the beneficial results, improve the adoption of the intention of the new product, when at low stress level, people will not pay more attention to the product (method) for the pursuit of the beneficial results, but will consider the new product to bring their own losses, thus reducing the willingness to adopt new products.

\section{Research Design and Data Analysis}

The purpose of this chapter is to form the research hypothesis of this paper, which is based on the main research contents of the paper, namely the influence of pressure level on the choice of new products and the mechanism of action, and the relationship between the variables proposed by the theoretical framework. The research model of this study is shown in Chart 1 .

\subsection{Research Design}

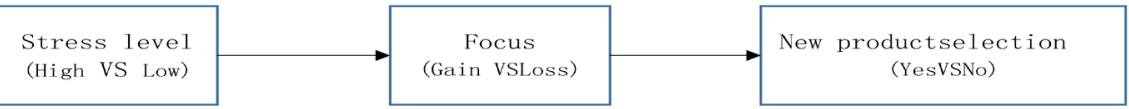

Chart 1. Research model.

\subsection{Experiment One: The Relation of Stress and New Product Selection}

The purpose of the experiment is to examine how the level of stress affects the 
consumer's choice of new products $\left(\mathrm{H}_{1}\right)$. The experimental design of single factor (stress level: High VS Low) was used in this experiment. The dependent variable is the choice of new products and old products. A total of 60 participants in the formal experiment were students from Jinan University. In the course of the experiment, 60 questionnaires were collected, and 53 valid questionnaires were obtained. 17 men accounted for $32.08 \%$, and 36 women accounted for $67.92 \%$. The average age was 20.15 , the youngest was 18 and the largest was 23 years old. The subjects were asked to try to imagine themselves as the protagonist in the reading story.

When individuals perceive that their own abilities and resources do not meet the requirements of achieving the goal, stress is created [20]. Therefore, the experiment chooses to manipulate the objective of the test to achieve the difficulty of the independent variable stress.

Then, the subjects were asked to fill in the stress control inspection scale. Next, the participants read the product information of the two commodities that helped achieve the target. A product is already available and widely accepted in the market. The other one is the new product that has just been introduced in the market. The advantages and disadvantages of the two products are listed. After reading the new and old product materials, the participants are required to make a choice between the two product options.

\subsubsection{Operation Inspection}

The mean value of eight questions in the test of stress level is the value of the perceived stress level in the test $(\alpha=0.91)$. Use single factor variance analysis. The stress levels $(m=5.5)$ in the group with high stress levels were significantly higher than those in the lower stress group $(\mathrm{m}=3.85 \mathrm{~F}(1,51)=24.77, \mathrm{p}<0.01)$. Therefore, it can be shown that the stress manipulation in this experiment is successful.

\subsubsection{New Product Selection}

In the selection of new products, the selected product will be labeled as 1, and the selection of old products will be marked as 0 . With the stress level as the independent variable, the selection of new products is the logistic regression analysis of the dependent variable. The results show that the main effect of stress level on new product selection is significant (support $\mathrm{H}_{1}$ ).

The subjects were more likely to choose a new product ( $80.0 \%$ vs. $42.9 \%)$ when they felt high stress (80\%) than when the subjects felt low stress (42.9\%). Wald $\chi^{2}=7.08, p=0.008<0.05$, as shown in Chart 2 .

\subsection{Equations Experiment Two: The Relationship between Stress, Focus and Adoption Intention}

The purpose of this experiment is to explore the intermediary mechanism of consumers choosing new products under stress level. A total of 106 participants in the formal experiment were students from Jinan University. In the course of 


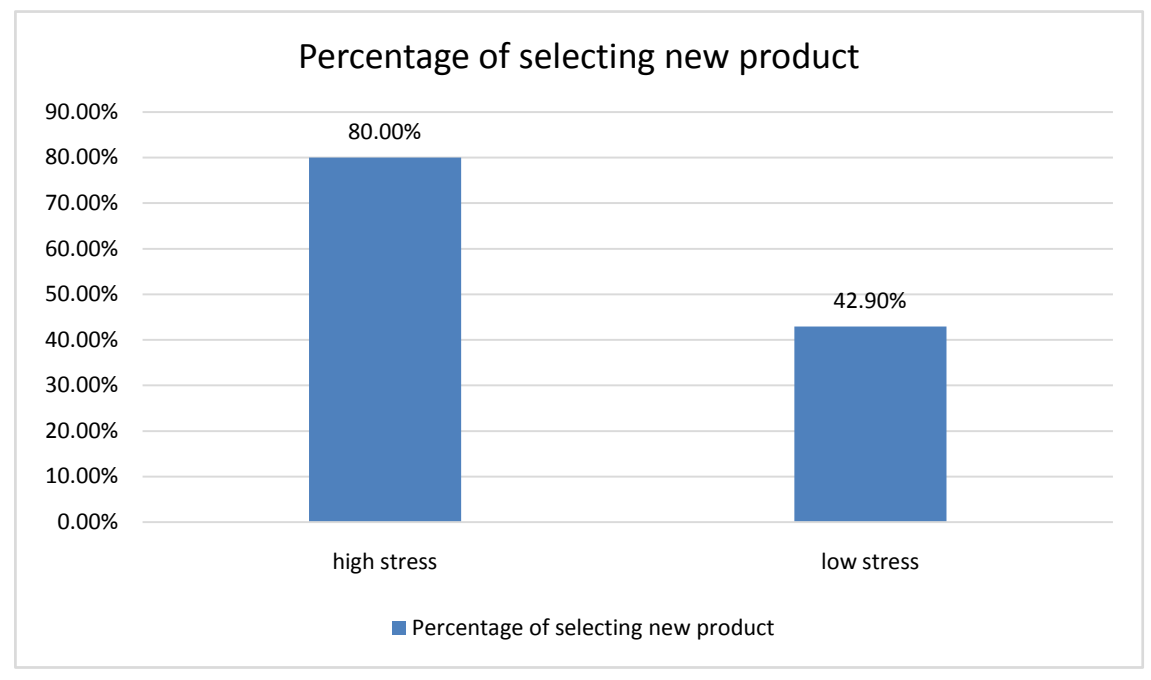

Chart 2. Percentage of selecting new product.

the experiment, 106 questionnaires were collected, and 99 valid questionnaires were obtained. 33 men accounted for $33.33 \%$, and 66 of women accounted for $66.67 \%$. The average age was 19.61, the youngest was 17 and the largest was 24 years old.

The experimental design of single factor (stress level: High VS Low) was used in this experiment. The dependent variable is the choice of new products and old products. All subjects were randomly assigned to 2 different experimental groups. The experiment is to collect the data by the way of the questionnaire, and the college students fill it out by recess time.

\subsubsection{Manipulation of Stress Levels}

This experiment is conducted in class. The two levels of stress were randomly assigned to class students. The experiment was related to health and subjects needed to try to imagine themselves as the protagonist in the story.

In the target chasing stage, the urgency of accomplishing the target time will trigger the stress perception, so this experiment chooses to manipulate the urgency of accomplishing the target to manipulate the goal of the subjects. Then, the subjects are required to fill in the stress control inspection scale. The participants then read the two product messages that helped cure the disease goal. One is an existing and widely accepted old product in the market. The other is the new product that has just been introduced in the market. The advantages and disadvantages of the two products are listed. After reading the new and old products, the participants are required to make a choice between the two product options.

The measurement of focus is to focus on the gains or losses of new products when testing the product selection. The participants read: "In making these product choices, I am concerned about the gains of new products or losses" ( $1=$ fully concerned about the losses, 9 = full focus on gains) the higher the score, the more the participants are concerned about the gains to the new product when 
making a choice. The lower the score, the more the participants are concerned about the losses to the new product when making a choice.

\subsubsection{Operation Inspection}

The mean value of eight questions in the test of stress level is the value of the perceived stress level in the test $(\alpha=0.95)$. With the stress level as the independent variable, the stress average perceived by the subjects as the dependent variable of univariate variance analysis, the results show that the stress level of manipulation is significant. The stress levels $(\mathrm{m}=7.21)$ in the group with high stress levels were significantly higher than those in the lower stress group $(\mathrm{m}=$ 5.39; $f(1,97)=71.71, p<0.001)$. Therefore, it can be shown that the stress manipulation in this experiment is successful.

\subsubsection{New Products Selection}

In the selection of new products, the selected new product will be labeled as 1 , and the selection of old products will be marked as 0 . The high stress control group was labeled 1 and the low stress group was labeled 0 . With the stress level as the independent variable, the selection of new products is the logistic regression analysis of the dependent variable. The results show that the main effect of stress level on new product selection is significant (support $\mathrm{H}_{1}$ ). Compared to the perceived low stress $(46 \%)$, the subjects were more likely to choose a new product $(67.3 \%)$ when they felt high stress $\left(67.3 \%\right.$ vs $46 \%$; Wald $\chi^{2}=4.51, \mathrm{p}=$ $0.03<0.05$; as shown in Chart 3 ).

\subsubsection{The Intermediary Role of the Focus}

With the stress level as the independent variable, the selection of new products is the logical regression analysis of the dependent variables, the results show that the main effect is significant $\left(\beta=0.88\right.$, Wald $\left.\chi^{2}=4.51, \mathrm{p}<0.05\right)$. With the stress level as the independent variable, the focus as the dependent variable for simple

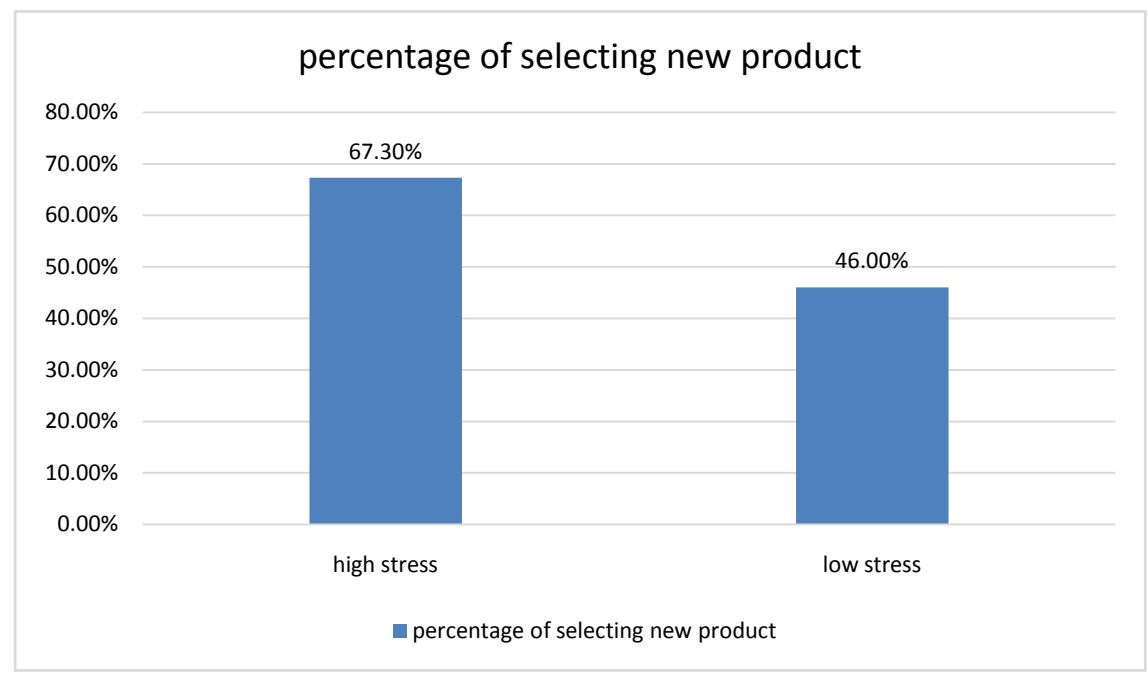

Chart 3. Percentage of selecting new product. 
linear regression analysis, the results showed that the main effect of stress level on the focus was significant $(\beta=0.98, \mathrm{p}<0.05)$. With the stress level and the focus as the independent variable, the selection of new products is the logical regression analysis of the dependent variables. The results showed that the effect of stress level on new product selection was not significant $\left(\beta=0.33\right.$, Wald $\chi^{2}=$ $0.43, \mathrm{p}>0.50$ ), but the effect of focus on new product selection was significant ( $\beta$ $=0.94$, Wald $\left.\chi^{2}=18.91, \mathrm{p}<0.001\right)$.

Secondly, the use of bootstrap analysis [21] was tested for mediating effects. The results show that in the $95 \%$ confidence interval, the results of the standardization of the intermediate test coefficients do not contain 0 (LLCI $=0.1549$, $\mathrm{ULCI}=0.9483$ ), indicating that the intermediary effect of the focus is significant. The mediating effect size is 0.4640 . The level of independent variable stress has no significant effect on the intention of new product purchase because the interval (LLCI $=-0.3253$, ULCI $=0.6515)$ contains 0 . Therefore, the focus on the stress level in the new product purchase will play a full intermediary role.

Based on the results of the above two mediating effects, the mediating effect of the focus point is significant (support $\mathrm{H}_{2}$ ).

\section{Conclusion and Innovation of Thesis}

\subsection{Conclusion}

The empirical research of this paper has carried on the research to the consumer new product choice behavior, mainly discussed the influence factors of stress perception on consumers' new product selection. The main conclusions of this study include the following:

The results of experiment one and experiment two show that the consumers' perception of the stress in the target chasing process will affect the consumers' choice of new products. In the experiment, consumers are more likely to choose a new product when the perceived stress of the consumer is at a high level. While manipulating consumers at low stress levels, consumers are more concerned about the losses from products and more reluctant to choose new products.

\subsection{Innovation of Thesis}

1) In previous studies, the gap between narrowing and goal is mainly three ways, one is to manage the target [22]; the second is to improve their own factors (capacity); Three is to find more effective methods/tools to accomplish the goal [23]. Compared to the first two ways to narrow the gap with the goal, finding more effective methods/tools to collaborate on goals is a more effective and direct way. However, the existing research is limited to the choice of the approach to the target time [22]. The research on method selection and replacement is scarce. This study discussed the change of the stress state level to the choice of auxiliary target realization method in the target chasing process, perfected the research of the goal realization way. 
2) Studies have shown that people change past consumption habits in response to stress [3]. But in the existing stress literature, the scholar mainly discusses the individual in the life situation coping with all kinds of stress strategy [24]. The study of stress is mainly focused on behavioral and social sciences, in the field of marketing, the study of stress status has been neglected [2]. The research on the influence of the stress state on the consumers' decision in the process of the goal chasing is perfect.

3) Many of the things that consumers do in the pursuit of a goal are influenced by goals, while consumer researchers rarely pay attention to goal-oriented consumer behavior [1]. This study improved the research of target-oriented consumer behavior.

\subsection{Limitations}

1) Limitations of experimental samples

The participants in this study only involved in the university students, only part of the consumer marketing environment in the consumer range more extensive. Therefore, in the future study, we should enlarge the group species of the subjects as far as possible, and discuss whether there are differences in the choice of new products among the consumers of many groups.

2) Limitations of the experimental environment

This research uses the questionnaire survey method, and the real shopping environment and the shopping scene has the certain difference, causes the research method which this research uses has the limitation. For the subjects, there is a certain distance between the shopping scene and the real shopping scene in reality, which will be different from the actual consumer decision scene. In addition, a certain distance from the real shopping scene will make the participants in the questionnaire fill a low involvement degree, the participants in the low level of choice and decision-making will be less serious and input. Therefore, in the future study should try to choose a high degree of authenticity of the experimental environment.

\section{Funding}

This work was funded by case study projects of Enterprise transformation development of the institute for enterprise development, Jinan University (No. 2017AL002).

\section{References}

[1] Baumgartner, H. and Pieters, R. (2008) Goal-Directed Consumer Behavior: Motivation, Volition, and Affect. Handbook of Consumer Psychology, 367-392.

[2] Moschis, G.P. (2007) Stress and Consumer Behavior. Journal of the Academy of Marketing Science, 35, 430-444. https://doi.org/10.1007/s11747-007-0035-3

[3] Lee, E., Moschis, G.P. and Mathur, A. (2001) A Study of Life Events and Changes in Patronage Preferences. Journal of Business Research, 54, 25-38. https://doi.org/10.1016/S0148-2963(00)00116-8 
[4] Cierpicki, S., Wright, M. and Sharp, B. (2000) Managers' Knowledge of Marketing Principles: The Case of New Product Development. Journal of Empirical Generalisations in Marketing Science, 5, 771-790.

[5] Rogers, E.M. (1995) Diffusion of Innovations. 3rd Edition, The Free Press, New York.

[6] Dickerson, M.D. and Gentry, J.W. (1983) Characteristics of Adopters and Non-Adopters of Home Computers. Journal of Consumer Research, 10, 225-235. https://doi.org/10.1086/208961

[7] Zhang, Y. and Huang, S.-C. (2010) How Endowed versus Earned Progress Affects Consumer Goal Commitment and Motivation. Journal of Consumer Research, 37, 641-654. https://doi.org/10.1086/655417

[8] Aristotle (1953) Nichomachean Ethics. Tomas, J.A.K., Trans. Penguin Classics, London.

[9] Ostlund, L.E. (1974) Perceived Innovation Attributes as Predictors of Innovativeness. Journal of Consumer Research, 1, 23-29. https://doi.org/10.1086/208587

[10] Moreau, C.P., Lehmann, D.R. and Markman, A.B. (2001) Entrenched Knowledge Structures and Consumer Response to New Products. Journal of Marketing Research, 38, 14-29. https://doi.org/10.1509/jmkr.38.1.14.18836

[11] Mitchell, V., Davies, F., Moutinho, L. and Vassos, V. (1999) Using Neural Networks to Understand Service Risk in the Holiday Product. Journal of Business Research, 46, 167-180. https://doi.org/10.1016/S0148-2963(98)00020-4

[12] Folkman, S., Lazarus, R.S., Gruen, R.J. and Delongis, A. (1986) Appraisal, Coping, Health Status, and Psychological Symptoms. Journal of Personality \& Social Psychology, 50, 571-579. https://doi.org/10.1037/0022-3514.50.3.571

[13] Etkin, J. and Rebecca, K.R. (2012) The Dynamic Impact of Variety among Means on Motivation. Journal of Consumer Research, 38, 1076-1092. https://doi.org/10.1086/661229

[14] Fishbach, A., Zhang, Y. and Dhar, R. (2007) When Thinking Beats Doing: The Role of Optimistic Expectations in Goal-Based Choice. Journal of Consumer Research, 34, 567-578. https://doi.org/10.1086/520071

[15] Verhallen, T.M.M. and Pieters, R.G.M. (1984) Attitude Theory and Behavioral Costs. Journal of Economic Psychology, 5, 223-249.

https://doi.org/10.1016/0167-4870(84)90024-2

[16] Lu, C.B., Qin, Q.X. and Lin, Y.Y. (2013) The Cognitive Mechanism of Consumer Purchase Decision in False Promotion: Empirical Research Based on Time Pressure and Overconfidence. Nankai Administration Review, 16, 92-103.

[17] Wang, T. and Cao, Z.S. (2007) Relationship Pressure in Relationship Marketing and Its Influence on Customer Loyalty. Finance and Economics, No. 5, 117-122.

[18] Laran, J., Janiszewski, C. and Cunha, M. (2008) Context-Dependent Effects of Goal Primes. Journal of Consumer Research, 35, 653-667. https://doi.org/10.1086/592127

[19] Garcia, R. (2007) Co-Opetition for the Diffusion of Resistant Innovations: A Case Study in the Global Wine Industry Using an Agent-Based Model. 25t $h$ International Conference of the System Dynamics Society, Vol. 3.

[20] Folkman, S. (1984) Personal Control and Stress and Coping Processes: A Theoretical Analysis. Journal of Personality \& Social Psychology, 46, 839-852. https://doi.org/10.1037/0022-3514.46.4.839

[21] Hayes, A.F. (2013) Introduction to Mediation, Moderation, and Conditional Process Analysis: Aregression-Based Approach. Journal of Educational Measure- 
ment, 51, 335-337.

[22] Fishbach, A., Dhar, R. and Zhang, Y. (2006) Subgoals as Substitutes or Complements: The Role of Goal Accessibility. Journal of Personality and Social Psychology, 91, 232-242. https://doi.org/10.1037/0022-3514.91.2.232

[23] Etkin, J. and Ratner, R.K. (2013) Goal Pursuit, Now and Later: Temporal Compatibility of Different versus Similar Means. Journal of Consumer Research, 39, 1085-1099. https://doi.org/10.1086/667203

[24] Connor-Smith, J.K. and Flachsbart, C. (2008) Relations between Personality and Coping: A Meta-Analysis. Journal of Personality \& Social Psychology, 93, 1080-1107. https://doi.org/10.1037/0022-3514.93.6.1080 